\title{
Acute renal failure as a form of presentation of sarcoidosis in a young adult: a case report
}

\author{
Joana Rema ${ }^{1 *}$, Margarida Carvalho1, Raquel Vaz², Margarida Fonseca², Susana Sampaio², Augusta Praça², \\ Margarida Freitas-Silva ${ }^{1}$ and Teresa Cardoso ${ }^{1}$
}

\begin{abstract}
Introduction: Sarcoidosis is a systemic granulomatous disease. Renal involvement is a rare initial presentation of this disease. Few articles on renal involvement as an initial presentation of sarcoidosis have been published in the literature.

Case presentation: A 26-year-old Caucasian woman presented with acute renal failure as an initial manifestation of sarcoidosis.

Conclusions: Renal involvement is an uncommon feature of sarcoidosis and it is essential to establish a fast and correct diagnosis because early therapy avoids progression to terminal renal failure.
\end{abstract}

Keywords: Acute renal failure, Granulomatous tubulointerstitial nephritis, Sarcoidosis

\section{Introduction}

Sarcoidosis is a systemic disease caused by noncaseating granulomas in multiple organs [1]. Its etiology is unknown [2]. In Caucasians, the prevalence is estimated to be 20 to 50 per 100,000 people [3]. The incidence of the disease is $16.5 / 100,000$ and 19/100,000 in men and women, respectively [4]. Renal manifestations of sarcoidosis include changes in calcium metabolism, nephrocalcinosis and nephrolithiasis. Some studies have shown that granulomatous tubulointerstitial nephritis is associated with acute renal failure and may lead to hemodialysis. The standard treatment is based on corticosteroids. Failure to respond to corticosteroids or relapse after withdrawal may be associated with worsening of renal failure, requiring dialysis and even kidney transplantation [5].

\section{Case presentation}

A 26-year-old Caucasian woman with a previous history of nephrolithiasis with renal colic episodes for the last 8 years, presented in the emergency department with nausea and anorexia. Her laboratory blood count revealed anemia with hemoglobin of $11.5 \mathrm{~g} / \mathrm{dL}$ (normal range: 12 to 16 ), leucopenia $3.61 \times 10^{9} / \mathrm{L}$ (4 to 11 ), acute renal failure with

\footnotetext{
* Correspondence: joana.rema@gmail.com

'Department of Internal Medicine, Centro Hospitalar de São João, E.P.E,

Alameda Professor Hernâni Monteiro, 4200-319 Porto, Portugal

Full list of author information is available at the end of the article
}

blood urea nitrogen of $43 \mathrm{mg} / \mathrm{dL}$ (10 to 50 ) and serum creatinine $1.6 \mathrm{mg} / \mathrm{dL}$ (0.6 to 1.1$)$. The urinary sediment had $0.3 \mathrm{~g} / \mathrm{L}$ proteins and erythrocytes (most did not lyse). There were no eosinophils. The objective examination remained with no alterations. No fever was documented. On analysis, we observed that her renal function was worsening with maximum creatinine of $2 \mathrm{mg} / \mathrm{dL}$ on the 3rd day. The inflammatory markers in the form of C-reactive protein were $45 \mathrm{mg} / \mathrm{L} \quad(<3.0 \mathrm{mg} / \mathrm{L})$. There was hypercalcemia of $2.88 \mathrm{mEq} / \mathrm{L}$ (2.26 to 2.64$)$ with correction by albuminemia giving ionized calcium of $5.9 \mathrm{mg} / \mathrm{dL}$ ( 4.6 to $5.4 \mathrm{mg} / \mathrm{dL}$ ). Her angiotensin-converting enzyme was elevated: $76 \mathrm{U} / \mathrm{L}$ $(<52 \mathrm{U} / \mathrm{L})$. Her 24-hour urine revealed no hypercalciuria and the assay of total protein per 24 hours was $1.03 \mathrm{~g}$. Her thyroid function was unchanged. Her parathormone was normal. An immunological study was negative. Viral serology showed no evidence of an acute infection; mycobacteriologic infection was excluded. A chest X-ray revealed a bilateral hilar lymphadenopathy. Abdominal and renal ultrasound documented splenomegaly, enlarged kidneys (right, $13.5 \mathrm{~cm}$; left, $13.9 \mathrm{~cm}$ ) with regular contours and preservation of the sinus parenchyma differentiation. A chest computed tomography revealed pulmonary micronodules (Figure 1). Pulmonary function tests revealed no alterations.

A renal biopsy was performed and revealed nine glomeruli in light microscopy, one sclerotic, and the presence 


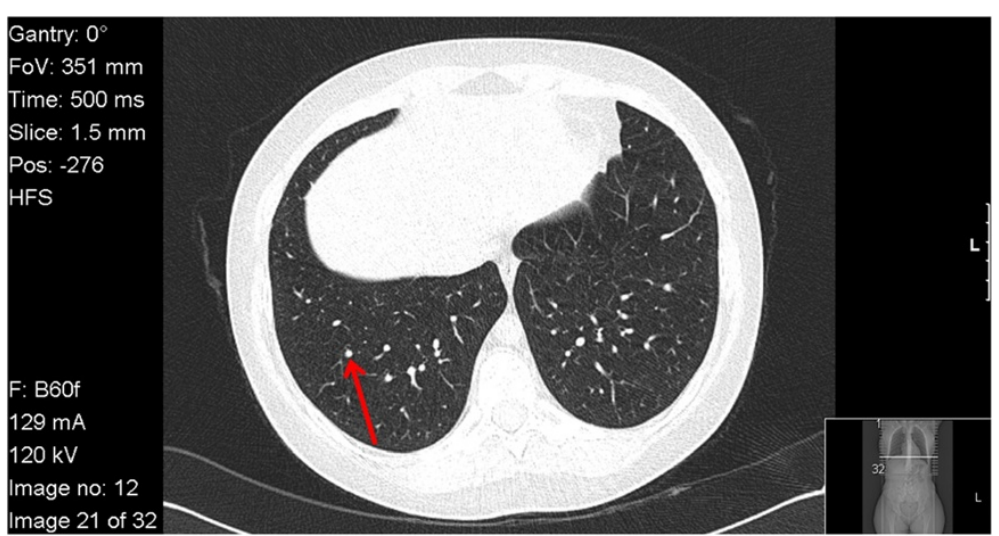

Figure 1 Thorax computed tomography scan of the patient, showing micronodules (indicated by an arrow).

of tubular necrosis and tubular atrophy. The renal biopsy showed interstitial severe inflammatory infiltrate lymphocytes and plasma cells, eosinophils and epithelioid macrophages with formation of granulomas with giant cells (Figure 2).

The histopathology report indicated granulomatous tubulointerstitial nephritis compatible with the diagnosis of sarcoidosis.

Other systems were studied for the possible involvement of sarcoidosis and revealed no alterations: the patient was submitted to an eye examination to exclude uveitis, there were no skin or articular lesions such as erythema nodosum, lupus pernio or arthritis, no liver function test abnormalities, an electrocardiogram revealed no intraventricular conduction defect or nodal block and an echocardiogram was also normal. She had no neurological signs namely cranial neuropathy.

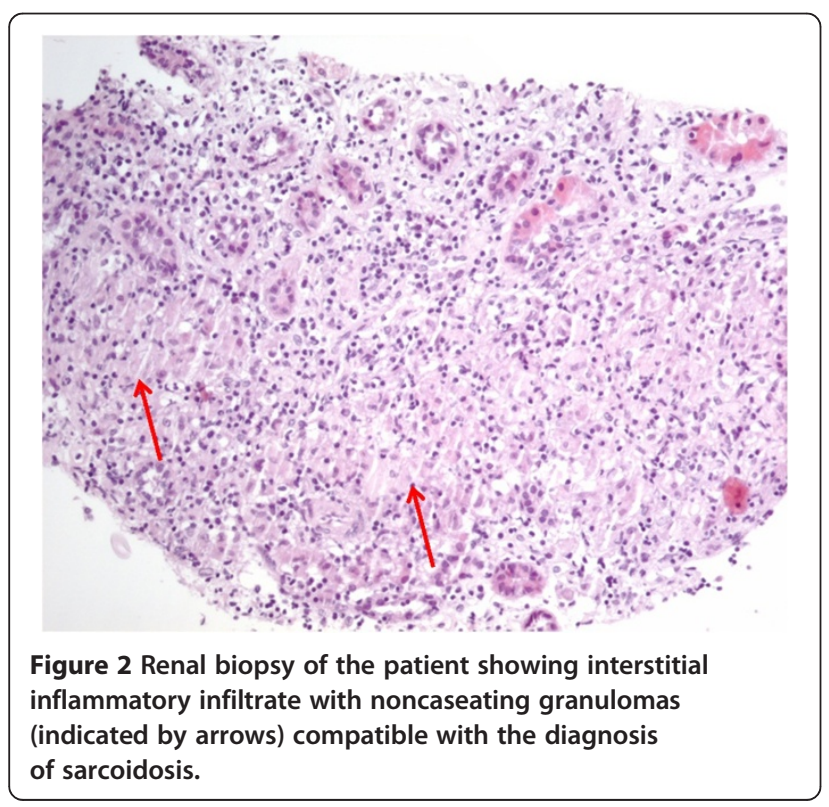

She started corticosteroid initially with three pulses of methylprednisolone $1 \mathrm{~g}$ daily for 3 consecutive days and then steroids in the form of oral prednisolone $1 \mathrm{mg} / \mathrm{kg} /$ day. On further observation after 3 weeks of steroid therapy, she presented with no anemia or leucopenia, and a normalization of her renal function and proteinuria per 24 hours (Figure 3) was observed.

In terms of follow-up, she has been followed under an out-patient regimen; her hemogram and renal function remain unchanged and are associated with no alterations in physical examination despite corticosteroid weaning.

\section{Discussion}

Sarcoidosis is a multisystem disease of unknown etiology; the lungs and lymph nodes are most commonly involved (30 to $60 \%$ of cases). Hypercalcemia (2 to $10 \%$ ) and hypercalciuria (6 to 30\%) can cause nephrocalcinosis and nephrolithiasis. The prevalence of tubulointerstitial nephritis varies between 7 and 27\%, and spite of chronic renal failure develops in less than $1 \%$ of cases according to different retrospective studies [6]. The spectrum of renal involvement in sarcoidosis includes hypercalcemia, nephrocalcinosis and interstitial granulomas [7]. Glomerular involvement in sarcoidosis is not common, although focal segmental sclerosis, membranous glomerulonephritis, mesangioproliferative glomerulonephritis, mesangiocapillary glomerulonephritis, immunoglobulin A nephropathy, and crescentic glomerulonephritis have all been described although their mechanisms are not known. Membranous nephropathy has been most commonly reported. Enhanced production of immunoglobulins may be involved in the pathogenesis of membranous glomerulonephritis, but neither an antigen nor a specific antibody has been identified [8].

Sarcoidosis is not only a pulmonary or renal disease but a systemic disease that can affect any organ in the body. The most common extrapulmonary organs affected are the eye and skin. Other than the lungs, neurological and 


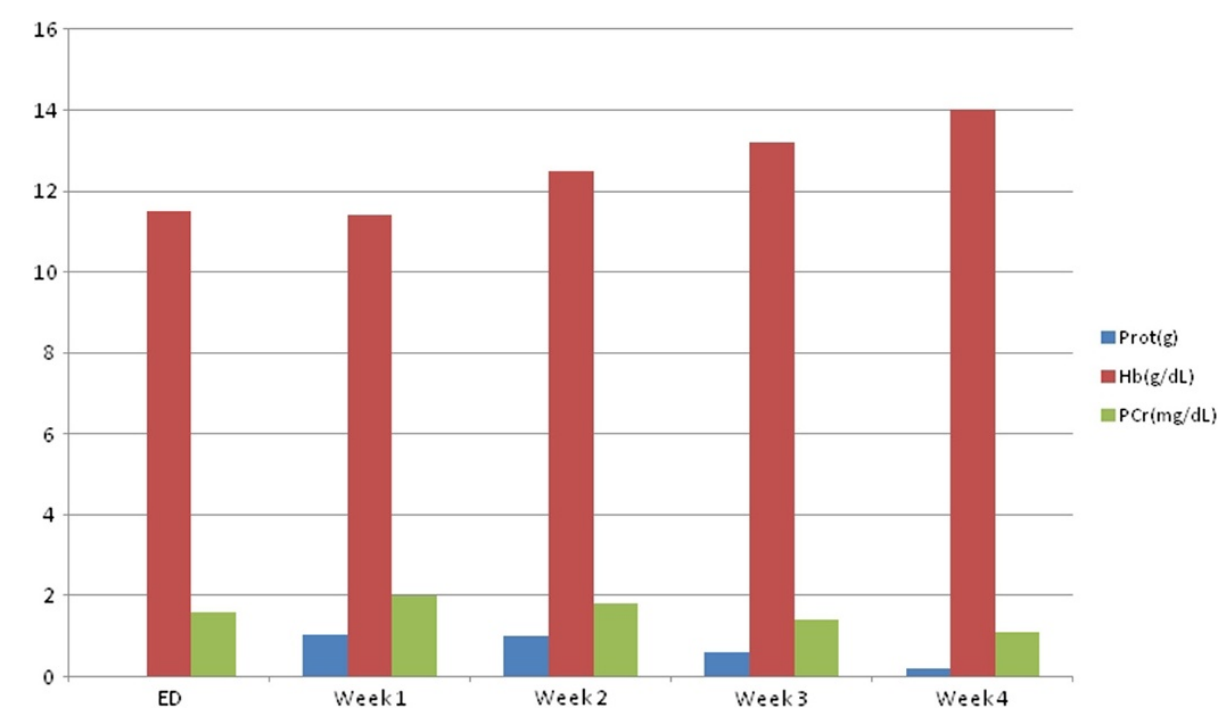

Figure 3 Graphic showing the evolution of proteinuria per 24 hours; hemoglobin and renal function from admission to our emergency department to week 4. Corticosteroids were started at the end of the first week. Abbreviations: ED, emergency department; Hb, hemoglobin; $\mathrm{PCr}$, plasma creatinine; Prot, proteinuria per 24 hours.

cardiac involvement must be excluded. The heart can manifest with mechanical and/or conduction defects. Central nervous system manifestations may present with cranial nerve symptoms (for example, VII, IX, X), with signs of optic chiasm involvement (for example, papilledema, blurred vision), meningeal symptoms caused by aseptic meningitis, symptoms of stroke/transient ischemic attack, and paresthesias. Patients may present with ophthalmologic or neuro-ophthalmologic findings before the systemic manifestations of sarcoidosis are seen. Ocular symptoms include uveitis and keratitis sicca. Musculoskeletal symptoms include myositis, bony lesions, and polyarthritis. Head, neck, and upper respiratory tract symptoms include dry cough, tonsillitis and epiglottitis; cardiac symptoms include cor pulmonale caused by pulmonary fibrosis, complete heart block, ventricular tachycardia most common arrhythmia, myocarditis, pericarditis, and congestive heart failure [9].

The mainstay of treatment is based on corticosteroids with good success rates [10]. In this case we can discuss whether nephrolithiasis was already in the context of a possible sarcoidosis because it is a common presentation of this multisystemic disease. It was essential to exclude possible infectious causes including tuberculosis in order to start treatment with corticosteroids. On further observation after 3 weeks of steroid therapy she presented with no anemia or leucopenia, and her renal function had normalized.

\section{Conclusion}

Although sarcoidosis usually presents with pulmonary and lymph nodes involvement, in the emergency of a young adult woman with acute renal failure it becomes imperative to focus on the correct diagnosis because early therapy is essential to avoid progression to terminal renal failure .

\section{Consent}

Written informed consent was obtained from the patient for publication of this case report and any accompanying images. A copy of the written consent is available for review by the Editor-in-Chief of this journal.

\section{Competing interests}

The authors declare that they have no competing interests.

\section{Authors' contributions}

JR, MC, MF, AP, MFS and MTC dealt directly with the patient, and contributed to the writing and editing of the manuscript. RV and SS contributed to the histological examination of the kidney. All authors read and approved the final manuscript.

\section{Acknowledgements}

We thank Prof. Dr Rui Medeiros for his support and suggestions. Permission for the acknowledgement was obtained from Prof. Dr Rui Medeiros.

\section{Sources of funding}

There were no sources of funding for all the authors.

\section{Author details}

'Department of Internal Medicine, Centro Hospitalar de São João, E.P.E, Alameda Professor Hernâni Monteiro, 4200-319 Porto, Portugal. ²Department of Nephrology, Centro Hospitalar de São João, E.P.E, Alameda Professor Hernâni Monteiro, 4200-319 Porto, Portugal.

Received: 25 August 2013 Accepted: 26 June 2014 Published: 13 August 2014

\section{References}

1. Mahévas M, Lescure F, Boffa J, Delastour V, Belenfant X, Chapelon C, Cordonnier C, Makdassi R, Piette JC, Naccache JM, Cadranel J, Duhaut P, 
Choukroun G, Ducroix JP, Valeyre D: Renal sarcoidosis. Clinical, laboratory, and histologic presentation and outcome in 47 patients. Medicine 2009, 88:98-106.

2. Kellinghaus C, Schilling M, Luderman P: Neurosarcoidosis: clinical experience and diagnostic pitfalls. Eur Neurol 2004, 51:84-88.

3. Stern BJ, Krumholz A, Johns C, Scott P, Nissim J: Sarcoidosis and its neurological manifestations. Arch Neurol 1985, 42:909-917.

4. Nunes H, Bouvry D, Soler P, Valeyre D: Sarcoidosis. Orphanet J Rare Dis 2007, 2:46

5. Shen SY, Hall-Craggs M, Posner JN, Shabazz B: Recurrent sarcoid granulomatous nephritis and reactive tuberculin skin test in a renal transplant recipient. Am J Med 1986, 80:699-702.

6. Gupta A, Khaira A: Sarcoidosis: diagnóstico a partir del estúdio de insuficiencia renal e hipercalcemia. Nefrologia 2011, 31(3):371-372.

7. Peces R, Laurés AS, Navascués RA, Baltar J, Seco M, Ortega F, Maríny R, Alvarez Grande J: El espectro de afectación renal en la sarcoidosis: presentación de tres casos. Nefrologia 1998, XVIII(2):161-164.

8. Sheffield EA: Pathology of sarcoidosis. Clin Chest Med 1997, 18:741-753.

9. Judson M: Extrapulmonary sarcoidosis. Semin Respir Crit Care Med 2007, 28:83-101.

10. Rajakariar R, Sharples EJ, Raftery MJ, Sheaff M, Yaqoob MM: Sarcoid tubulointerstitial nephritis: long-term outcome and response to corticosteroid therapy. Kidney Int 2006, 70:165-169.

doi:10.1186/1752-1947-8-274

Cite this article as: Rema et al:: Acute renal failure as a form of

presentation of sarcoidosis in a young adult: a case report. Journal of Medical Case Reports 2014 8:274.

\section{Submit your next manuscript to BioMed Central and take full advantage of:}

- Convenient online submission

- Thorough peer review

- No space constraints or color figure charges

- Immediate publication on acceptance

- Inclusion in PubMed, CAS, Scopus and Google Scholar

- Research which is freely available for redistribution 